\title{
NEUTRON FIELD MOCK-UP DEVELOPMENT FOR THE FLUORIDE SALT REACTORS NEUTRONIC RESEARCH
}

\author{
Evžen Losa, Michal Košt’ál, Tomáš Czakoj, Jan Šimon, Nicola Burianová, \\ Vlastimil Juříček, Vojtěch Rypar \\ Research Centre $\check{R} e \check{z}$, \\ 25068 Husinec- ̌̌ež 130, Czech Republic
}

evzen.losa@cvrez.cz

\begin{abstract}
Experimental work at the LR-0 reactor was carried out to determine the possibility of the mock-up neutron field creation for the fluoride salt-based reactors. Previous calculations and experiments have shown that the fast part of the molten salt reactor (MSR) spectrum is shaped by fluorine and even the Teflon material is suitable for neutronics in that energy range. Properly selected spectrum indices can describe the neutron field of the MSR in fast thermal and intermediate parts of the spectrum. Current research has focused on a deeper study of the possibility of using the filtered thermal and intermediate neutron spectrum of the experimental light water reactor for the physics of fluoride salt-based reactor. $\mathrm{LiF}_{-} \mathrm{BeF}_{2}$ (FLIBE) capsule and teflon cylinders are used as a spectrum filters in the LR-0 reactor. Measured results show acceptable $\mathrm{C} / \mathrm{E}-1$ agreement in the reaction rates and satisfactory agreement for usage of the FLIBE filtered neutron spectrum determined by the ${ }^{181} \mathrm{Ta}(\mathrm{n}, \gamma)$ monitor as a mock-up in thermal to intermediate energy in the fluoride high-temperature reactor (FHR). Concerning MSR, intermediate spectrum can be reproduced to some extent but not as good as in the case of FHR.
\end{abstract}

KEYWORDS: LR-0 reactor, MSR, FHR, neutron spectrum, spectral indices, reaction rates

\section{INTRODUCTION}

For reactor technology development, the good knowledge of neutronics plays a crucial role as the parameters of neutrons e.g. spectrum and flux can influence the criticality, safety parameters (feedbacks), or material aging. Previous studies have shown the idea to characterize the neutron spectrum of a molten salt reactor (MSR) by means of reaction rate ratios, the so-called spectrum indices, in the neutron field of a light-water research reactor (LWR) generated by an appropriate filter (see ref. [1]). It was concluded that the calculated spectral indices are sufficiently sensitive to changes in the fast neutron tails of different advanced reactor concepts; at the same time, the neutron spectrum of the MSR showed very good agreement with the filtered spectrum of the light water research reactor by the filter containing $\mathrm{LiF}_{-} \mathrm{BeF}_{2}$ (FLIBE) salt. Moreover, it has been found that the fast part of the MSR spectrum can be simulated in the LWR by other compounds than FLIBE, containing substantial amounts of bound fluorine, for example with Teflon [2]. Following these findings, other general issues must be resolved, such as measuring the spectrum indices with acceptable uncertainty, the extent to which the measurements correspond with calculations, and the precision of the thermal and epithermal part of the neutron spectrum description in the filtered LWR field 
and its correspondence with MSR and FHR reactors. For the aforementioned purposes, irradiation in the filtered neutron spectrum can be carried out in an experimental light water reactor.

Reaction rates measurement by means of material activation is a suitable tool for validation of the neutron field in the designed mock-up. The selection of proper material for activation monitors facilitates the neutron spectrum characterization in the thermal and intermediate range via different reaction energy sensitivities. Fig. 1 shows the energy dependence of several $(n, g)$ reactions in terms of their cumulative contribution to the total reaction rate in the thermal and intermediate neutron spectrum. This figure demonstrates how sensitive the different materials are in the observed part of the neutron spectrum, and based on the reaction evolution, proper monitors can be selected for the experiments described in the following paragraphs.

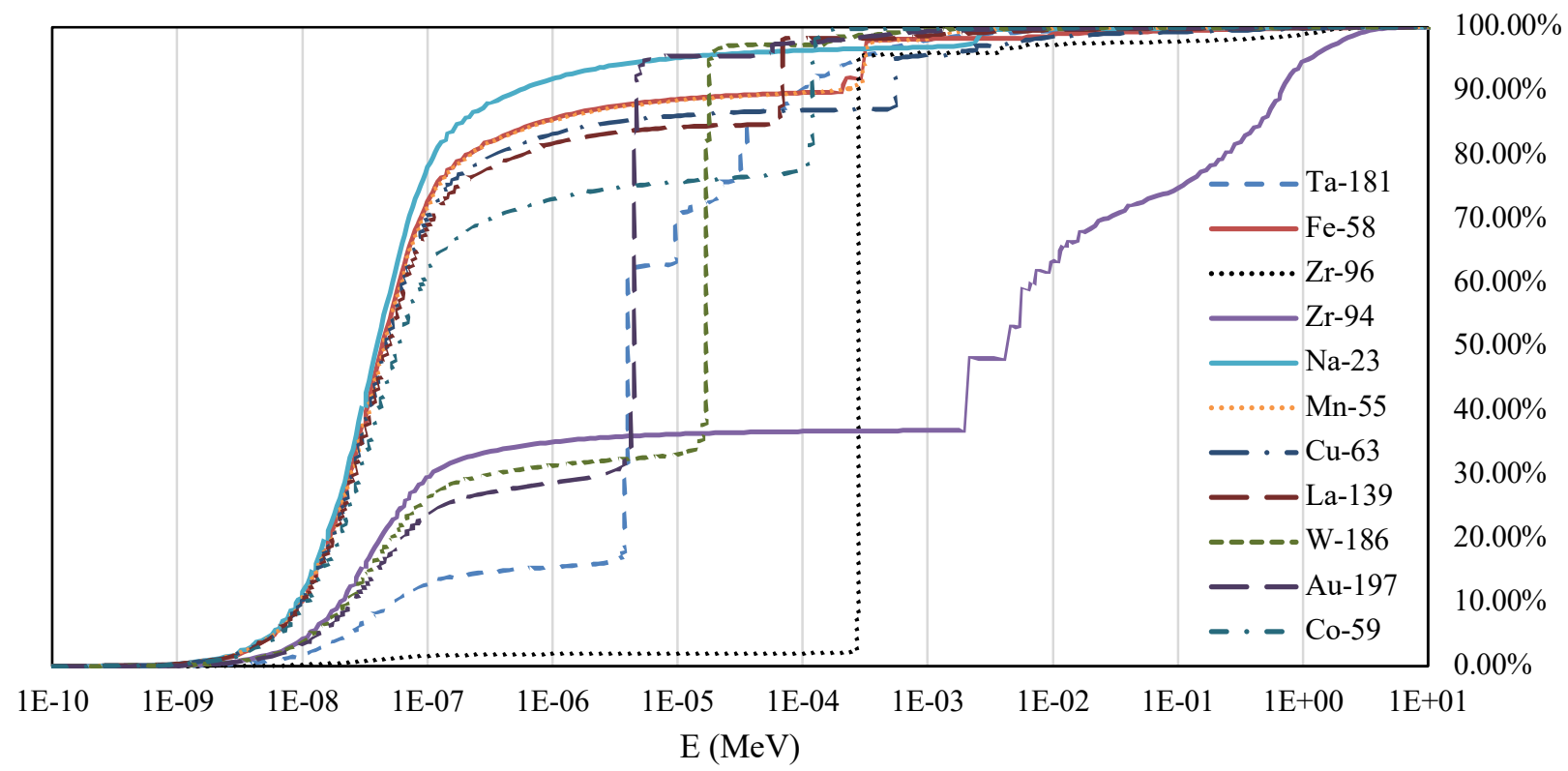

Figure 1. Cumulative reaction rates calculated in LR-0 core

\section{MATERIALS AND METHODS}

\subsection{Modules with FLIBE Salt and Teflon}

Described approach used filters for neutron spectrum shaping. Filter, or irradiation module, can be inserted into the dry channel in the reactor core. The FLIBE filter consists of a stainless-steel vessel of a diameter of $20 \mathrm{~cm}$ with a mixture of lithium beryllium fluoride salt. It has six cavities for sample irradiation in the filtered neutron spectrum. In the center of the module, there is a larger cavity (inner diameter $6.4 \mathrm{~cm}$ ) into which a spectrometric device can be inserted. The vessel was pre-heated and the melted FLIBE salt was poured into it to have compact form. As it is, the module is suited for experiments at room temperature. Total amount of the FLIBE salt contained in the vessel is $27.54 \mathrm{~kg}$. The height of the FLIBE column in the vessel is $52 \mathrm{~cm}$ which corresponds to the height of $53.6 \mathrm{~cm}$ above the fuel column lower end. The rods for insertion of activation foils are placed in smaller cavities (see Fig. 2 left) and numbered as in Fig. 3. In axial direction, levels 3, 4, 5, 6, 7 (Table III) correspond to heights of 11.7, 16.7, 21.7, 26.7, and $31.7 \mathrm{~cm}$. The values are related to the beginning of the fission column level (active part of the fuel), where $0 \mathrm{~cm}$ represents the lower end of the fission column. 
Teflon insertion has the shape of a simple cylinder with the central cavity for neutron spectrum measurement and irradiation. The cylinder outer diameter is $20.5 \mathrm{~cm}$. For irradiation, the foil carrier in the form of aluminum rod with spacer is used as displayed in Fig. 2.
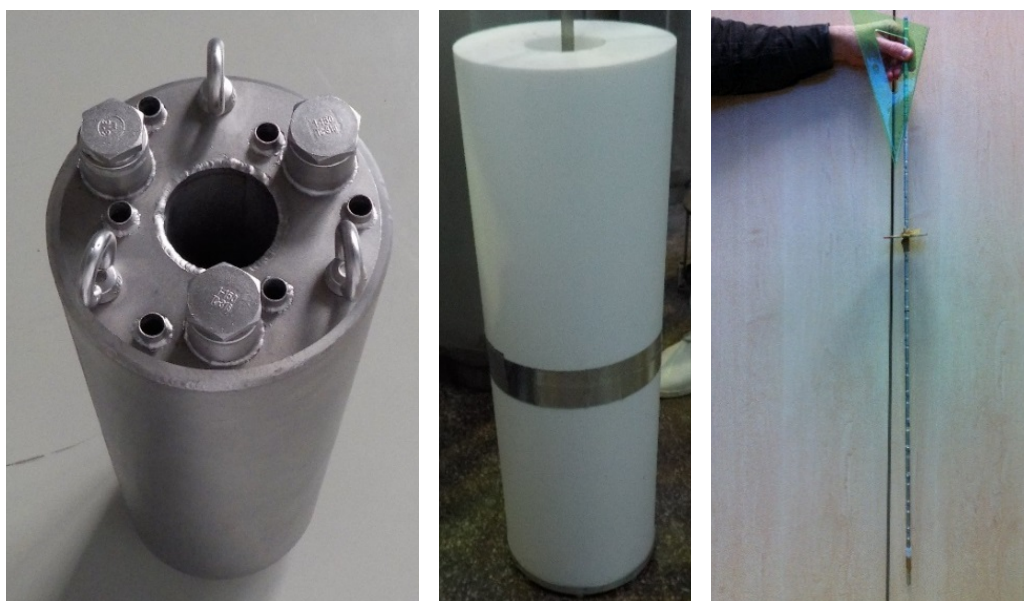

Figure 2. From the left: FLIBE module, Teflon module, activation foil carrier.

\subsection{Activation Materials}

To characterize thermal and intermediate part of the neutron spectrum, primarily materials with different $(\mathrm{n}, \gamma)$ reaction evolutions, as shown in Fig. 1, are used. Several materials were chosen for experimental study of reaction rate in FLIBE and Teflon modules. The FLIBE experiment was focused purely on $(\mathrm{n}, \gamma)$ reactions, while for Teflon $(n, p),(n, \alpha)$, and $(n, 2 n)$ reactions were further studied. For the FLIBE module, materials have been selected as follows: $\mathrm{Mn}, \mathrm{Au}, \mathrm{Co} \mathrm{Ta}$ and their placement in the module was done as shown in Tab. I. Different sets of activation foils, $\mathrm{Au}, \mathrm{Co}, \mathrm{Ti}, \mathrm{Fe}, \mathrm{Ni}, \mathrm{Al}$ were used for irradiation in the Teflon module. Radioactive products of the irradiation in the filtered neutron field are detected by the semiconductor high purity germanium detector (HPGe) with verified material and geometry data.
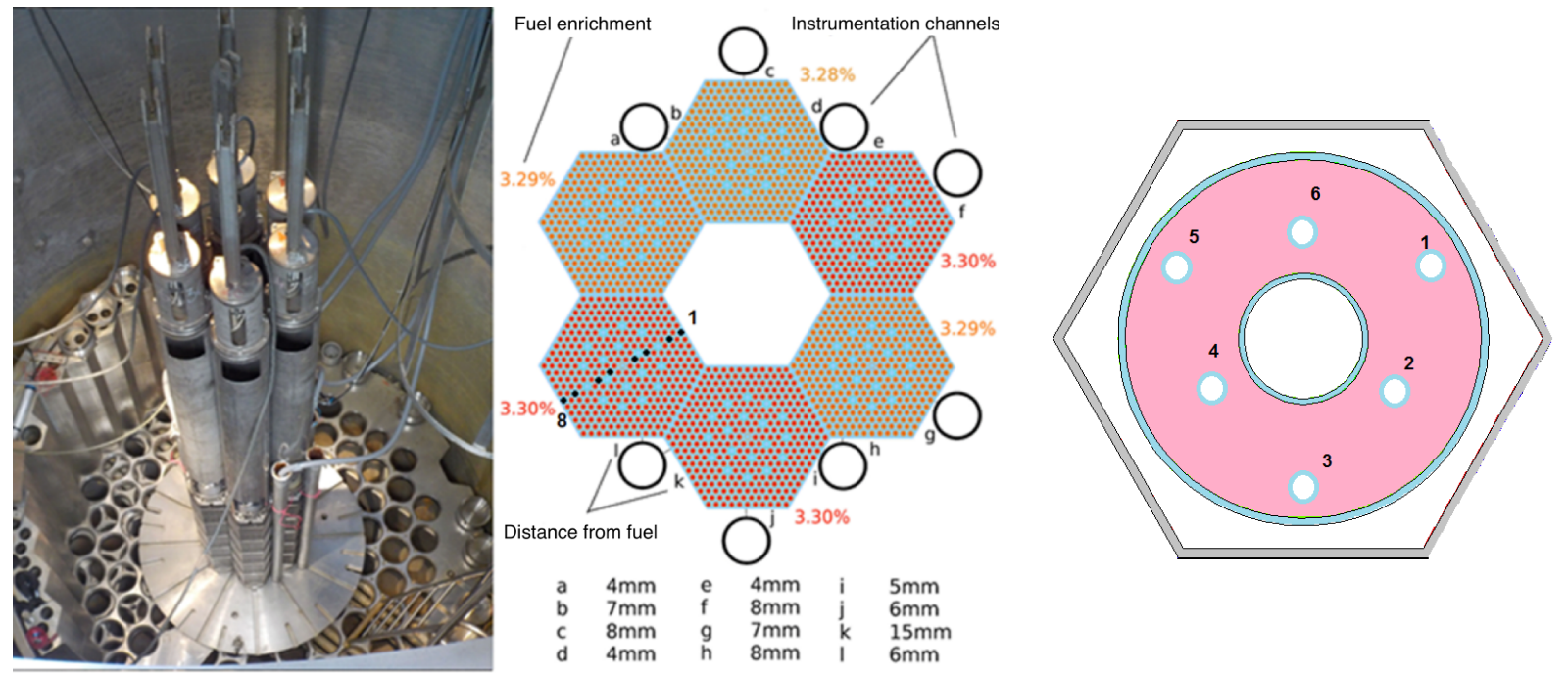

Figure 3. Overhead view of the core, its scheme and scheme of the FLIBE module. 


\subsection{LR-0 Reactor}

Irradiation of the module was carried out at the LR-0 reactor operated by Research Centre Řež. The LR-0 reactor is a zero-power reactor based on light water pool-type technology. Fuel burn-up is not measurable thanks to the low flux; thus, it can be considered as fresh for all calculations. However, the power is sufficient enough to cause activation of materials in the core center and its vicinity.

The core is composed of six hexagonal fuel assemblies consisting of the same number of pins and having the same face-to-face dimensions as the VVER-1000 fuel. This type of core has been benchmarked [3] in past and the reactivity [4], spatial flux distribution [5], spectrum [6], and power distribution [7] have been characterized. Thus, it acts today as a reference neutron field [8].

Specialty of the benchmark core in the LR-0 reactor is that the criticality is given by the amount of moderator while the control rods are withdrawn to upper position. Water level is then considered as a critical parameter which can be measured with low uncertainty.

\subsection{Calculations}

Neutron spectrum and reaction rates of the irradiated foils in the LR-0 reactor have been calculated in critical mode of the MCNP6.2 [9], where the material data characteristics have been defined in the ENDF/BVII.0 [10] data library. Target materials were defined in other nuclear data libraries as well to observe their sensitivity on the library choice. Neutron spectrum in FHR and MSR reactors has been calculated by Serpent 2 code [11] in version 2.1.30, ENDF/B-VII.0 nuclear data library has been used for these calculations as well. Temperature of all models has been set to $294 \mathrm{~K}$.

\section{RESULTS}

\subsection{Neutron spectrum}

Firstly, the comparison of the expected neutron spectra obtained from calculation models is shown in Fig. 4, where the case "Empty channel" means the central channel without neutron filter, "Teflon" and "FLIBE" are referencing the filters accordingly, "MSR" is a generic model of the single fluid molten salt reactor and "FHR" is the spectrum in the coolant of the small reactor with the plank microparticle fuel [12]. The neutron spectra were calculated in the 640 group (SAND-II) format and are normalized in energies from $0.002 \mathrm{eV}$ to $0.2 \mathrm{eV}$ (to the thermal energy peak at room temperature).

Calculated fluxes were integrated into 3 groups $(1 \mathrm{meV}-1 \mathrm{eV}, 1 \mathrm{eV}-10 \mathrm{keV}$, and above $10 \mathrm{keV})$ representing thermal, intermediate, and fast group for the purpose of comparison. It can be seen that the largest portion of the thermal neutrons is present in the MSR system, where only fluid homogeneous fuel is used. The FHR concept is right behind the MSR due to its micro-particle TRISO fuel, which can be considered as semi-homogeneous. Ratios of the neutron share according to their energies in the given spectra are shown in Tab. I. It was found that the thermal to intermediate neutron range of the FHR reactor can be simulated by the FLIBE insertion in the LR-0 reactor because the ratio between thermal and intermediate neutrons is very similar. However, for the monitors acting in the thermal to fast energy range, the Teflon insertion is more suitable. In the case of the MSR reactor, the neuron spectrum can be simulated in the LWR only from the intermediate to fast energy range with the rate of similarity of $70 \%$. The rates of similarity of the three-group spectrum representation are demonstrated in Tab. II. 


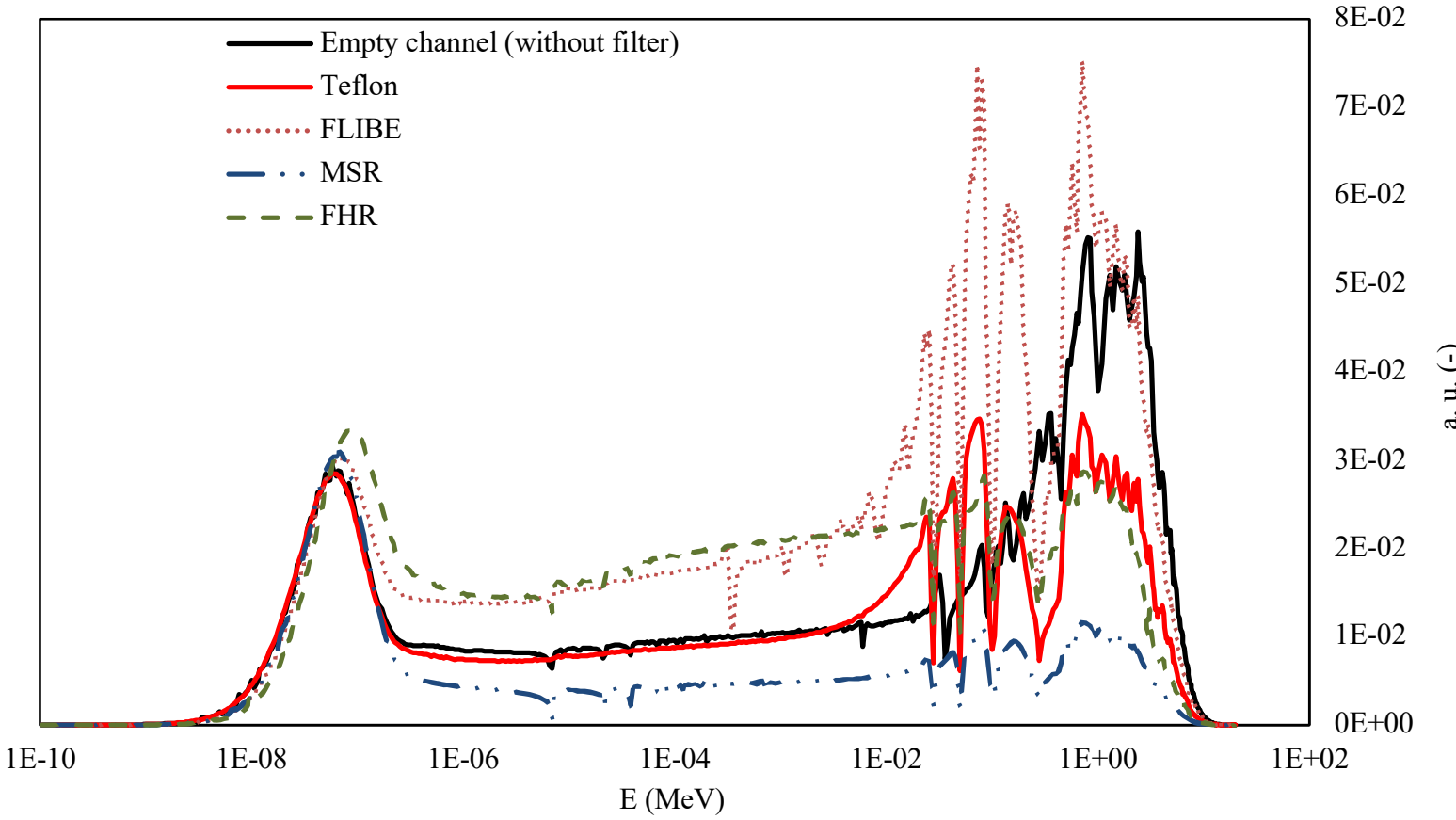

Figure 4. Comparison of the calculated neutron spectra in the LR-0 reactor with different insertions and reactor concepts using the fluoride molten salt.

Table I. Ratios of the group fluxes for different calculation models.

\begin{tabular}{|c|c|c|c|c|c|}
\hline & Empty ch. & Teflon & FLIBE & MSR & FHR \\
\hline Thermal/Intermediate & $82 \%$ & $84 \%$ & $51 \%$ & $163 \%$ & $52 \%$ \\
\hline Thermal/Fast & $35 \%$ & $48 \%$ & $29 \%$ & $131 \%$ & $64 \%$ \\
\hline Intermediate/Fast & $43 \%$ & $57 \%$ & $57 \%$ & $81 \%$ & $123 \%$ \\
\hline
\end{tabular}

Table II. Comparison of the different insertions' similarity.

\begin{tabular}{|c|c|c|c|}
\hline & $\begin{array}{c}\text { Thermal vs. } \\
\text { Intermediate }\end{array}$ & $\begin{array}{c}\text { Thermal vs. } \\
\text { Fast }\end{array}$ & $\begin{array}{c}\text { Intermediate vs. } \\
\text { Fast }\end{array}$ \\
\hline Teflon vs. FHR & $161.2 \%$ & $\mathbf{7 4 . 8 \%}$ & $46.4 \%$ \\
\hline FLIBE vs. FHR & $\mathbf{9 8 . 1 \%}$ & $45.2 \%$ & $46.1 \%$ \\
\hline Teflon vs. MSR & $51.3 \%$ & $36.4 \%$ & $\mathbf{7 0 . 9 \%}$ \\
\hline FLIBE vs. MSR & $31.2 \%$ & $22.0 \%$ & $\mathbf{7 0 . 4 \%}$ \\
\hline
\end{tabular}

\subsection{Reaction rates}

Monitors of the flux were selected according to the accessibility and response in the thermal, intermediate and fast part of the neutron spectrum. Calculations referred in previous paragraphs showed which insertions are suitable for simulating the different types of fluoride salt-based reactors.

Because the thermal/intermediate part of the spectrum in FLIBE is similar to the FHR, manganese, gold, cobalt, and tantalum were selected for more detailed description in this insertion (for their sensitivity see Fig. 1). The case where $\mathrm{Au}, \mathrm{Co}$, and Ta foils were covered by $\mathrm{Cd}$ sheets to suppress thermal flux was studied as well and foils placed in the $\mathrm{Cd}$ shrouds are denoted by (Cd) symbol in the Tab. III. Because the monitors 
were placed in different radial and axial positions of the module, neutron field distribution can be assessed directly from the evaluated experimental reaction rates. According to the reaction rates on manganese (see Tab. III), the thermal flux is homogeneously distributed in the FLIBE module on axial levels between 11.7 and $21.7 \mathrm{~cm}$ and does not depend on the thickness of the salt filter (see the carrier positions in the Fig. 3 right). The axial flux homogeneity is confirmed by reaction rates on gold as well. The C/E-1 column shows the percentual correspondence of the measurement with the calculation. All the differences between measured reaction rates are within experimental uncertainties. Thermal neutron field homogeneity is given by the low neutron leakage from the module and its strongly scattering properties. However, the scattering is caused not only by the FLIBE salt filling, but by the structural material of the module as well, which also contributes to the spectrum shaping. Mentioned experimental uncertainties have following components: uncertainty in measured net peak area (NPA), measurement uncertainty, uncertainty in calibration, uncertainty in detection efficiency, uncertainty in sample positioning, and uncertainty in nuclear data constants.

Table III. Measured and calculated reaction rates in the FLIBE module normalized to one target nucleus and neutron in the core.

\begin{tabular}{|c|c|c|c|c|c|c|c|}
\hline $\begin{array}{c}\text { Position } \\
\text { of the } \\
\text { rod }\end{array}$ & $\begin{array}{c}\text { Position } \\
\text { on the } \\
\text { rod }\end{array}$ & $\begin{array}{c}\text { Axial level } \\
(\mathrm{cm})\end{array}$ & $\begin{array}{c}\text { Activation } \\
\text { foil }\end{array}$ & Reaction & $\begin{array}{c}\text { Measured } \\
\text { reaction rate } \\
\left(\mathrm{s}^{-1}\right)\end{array}$ & C/E-1 & $\begin{array}{c}\text { Rel. } \\
\text { uncertainty }\end{array}$ \\
\hline 1 & 5 & 21.7 & $\mathrm{Mn} 1$ & ${ }^{55} \mathrm{Mn}(\mathrm{n}, \gamma)$ & $1.157 \mathrm{E}-26$ & $-9.77 \%$ & $4.7 \%$ \\
\hline 2 & 7 & 31.7 & $\mathrm{Au} 1(\mathrm{Cd})$ & ${ }^{197} \mathrm{Au}(\mathrm{n}, \gamma)$ & $6.258 \mathrm{E}-27$ & $5.99 \%$ & $4.7 \%$ \\
\hline 2 & 5 & 21.7 & $\mathrm{Au} 2$ & ${ }^{197} \mathrm{Au}(\mathrm{n}, \gamma)$ & $1.281 \mathrm{E}-26$ & $-13.70 \%$ & $4.6 \%$ \\
\hline 3 & 5 & 21.7 & $\mathrm{Co}(\mathrm{A})$ & ${ }^{59} \mathrm{Co}(\mathrm{n}, \gamma)$ & $2.498 \mathrm{E}-27$ & $1.67 \%$ & $5.0 \%$ \\
\hline 3 & 7 & 31.7 & $\mathrm{Co}(\mathrm{B}, \mathrm{Cd})$ & ${ }^{59} \mathrm{Co}(\mathrm{n}, \gamma)$ & $6.400 \mathrm{E}-28$ & $-9.02 \%$ & $5.0 \%$ \\
\hline 4 & 7 & 31.7 & $\mathrm{Ta} 3(\mathrm{Cd})$ & ${ }^{181} \mathrm{Ta}(\mathrm{n}, \gamma)$ & $3.012 \mathrm{E}-27$ & $1.36 \%$ & $4.8 \%$ \\
\hline 4 & 5 & 31.7 & $\mathrm{Ta} 4$ & ${ }^{181} \mathrm{Ta}(\mathrm{n}, \gamma)$ & $4.302 \mathrm{E}-27$ & $-0.06 \%$ & $4.7 \%$ \\
\hline 5 & 3 & 11.7 & $\mathrm{Mn} 4$ & ${ }^{55} \mathrm{Mn}(\mathrm{n}, \gamma)$ & $1.085 \mathrm{E}-26$ & $-16.24 \%$ & $10.3 \%$ \\
\hline 5 & 5 & 21.7 & $\mathrm{Mn} 5$ & ${ }^{55} \mathrm{Mn}(\mathrm{n}, \gamma)$ & $1.125 \mathrm{E}-26$ & $-11.02 \%$ & $4.7 \%$ \\
\hline 5 & 4 & 16.7 & $\mathrm{Au} 3$ & ${ }^{197} \mathrm{Au}(\mathrm{n}, \gamma)$ & $1.348 \mathrm{E}-26$ & $2.88 \%$ & $4.7 \%$ \\
\hline 5 & 6 & 26.7 & $\mathrm{Au} 4$ & ${ }^{197} \mathrm{Au}(\mathrm{n}, \gamma)$ & $1.351 \mathrm{E}-26$ & $-9.77 \%$ & $4.7 \%$ \\
\hline 6 & 5 & 21.7 & $\mathrm{Mn} 3$ & ${ }^{55} \mathrm{Mn}(\mathrm{n}, \gamma)$ & $1.060 \mathrm{E}-26$ & -9.08 & $4.7 \%$ \\
\hline
\end{tabular}

Table IV. Cadmium ratios of different thermal monitors, comparison of the reference case without insertion to FLIBE insertion.

\begin{tabular}{|c|c|c|c|c|c|c|}
\hline \multirow[b]{2}{*}{ Reaction } & LR-0 empty & \multicolumn{3}{|c|}{ LR-0 FLIBE } & FHR & MSR \\
\hline & $\begin{array}{c}\text { Measured Cd } \\
\text { ratio } \\
\end{array}$ & $\begin{array}{l}\text { Measured } \\
\text { Cd ratio }\end{array}$ & $\begin{array}{c}\text { Calculated } \\
\text { Cd ratio }\end{array}$ & C/E-1 & \multicolumn{2}{|c|}{ Calculated $\mathrm{Cd}$ ratio } \\
\hline${ }^{59} \operatorname{Co}(\mathrm{n}, \gamma)$ & 3.38 & 2.33 & 2.60 & $11.7 \%$ & 4.34 & 13.03 \\
\hline${ }^{197} \mathrm{Au}(\mathrm{n}, \gamma)$ & 1.39 & 1.23 & 1.13 & $-10.9 \%$ & 2.54 & 6.05 \\
\hline${ }^{181} \mathrm{Ta}(\mathrm{n}, \gamma)$ & 1.11 & 1.14 & 1.12 & $-1.4 \%$ & 1.25 & 1.94 \\
\hline
\end{tabular}

The shift in the thermal spectrum was tested by means of the cadmium ratios, which are the spectral quantities suitable for thermal spectrum assessment. Tab. IV shows that the measured and calculated Cd ratios in the FLIBE module agree very well in the case of Ta and are satisfactory for Au and Co as well, when the C/E-1 is in the order of $11 \%$. When compared with the empty channel (measurements without 
insertion) of the LR-0 reactor, the ratios of the monitors in the more thermal part of the spectrum are smaller in case of the FLIBE insertion, which points to a slight shift of the spectrum to the intermediate energies. $\mathrm{Cd}$ ratio on Ta, which is moved more to resonant region, is very similar in both types of the core. This observation agrees with the theory, because neutron slow-down in FLIBE module occurs on the heavier nuclei. However, the calculated $\mathrm{Cd}$ ratios of ${ }^{59} \mathrm{Co}(\mathrm{n}, \gamma)$ and ${ }^{197} \mathrm{Au}(\mathrm{n}, \gamma)$ in the FHR and MSR reactors indicate that the shape of thermal part of the spectrum for the LR-0 reactor is completely different. Therefore, it is only convenient to compare ratios of total amounts of thermal, epithermal, and fast neutrons in spectrum as shown above.

Table V. Measured reaction rates in the Teflon module normalized to one target nucleus and neutron in the core.

\begin{tabular}{|c|c|c|c|c|c|}
\hline $\begin{array}{l}\text { Position } \\
\text { on the rod }\end{array}$ & $\begin{array}{l}\text { Axial } \\
\text { level } \\
(\mathrm{cm})\end{array}$ & Reaction & $\begin{array}{l}\text { Reaction } \\
\text { rates }\end{array}$ & $\mathrm{C} / \mathrm{E}-1$ & $\begin{array}{c}\text { Rel. } \\
\text { uncertainty }\end{array}$ \\
\hline \multirow{2}{*}{4} & \multirow{2}{*}{16.7} & ${ }^{197} \mathrm{Au}(\mathrm{n}, \gamma)$ & $1.72 \mathrm{E}-26$ & $0.6 \%$ & $2.2 \%$ \\
\hline & & ${ }^{59} \mathrm{Co}(\mathrm{n}, \gamma)$ & $2.72 \mathrm{E}-27$ & $-5.4 \%$ & $2.2 \%$ \\
\hline \multirow{6}{*}{5} & \multirow{6}{*}{21.7} & ${ }^{58} \mathrm{Ni}(\mathrm{n}, \mathrm{p})$ & $5.12 \mathrm{E}-30$ & $-6.1 \%$ & $2.2 \%$ \\
\hline & & ${ }^{54} \mathrm{Fe}(\mathrm{n}, \mathrm{p})$ & $3.70 \mathrm{E}-30$ & $-3.4 \%$ & $2.7 \%$ \\
\hline & & ${ }^{46} \operatorname{Ti}(\mathrm{n}, \mathrm{p})$ & $4.83 \mathrm{E}-31$ & $12.8 \%$ & $6.6 \%$ \\
\hline & & ${ }^{47} \mathrm{Ti}(\mathrm{n}, \mathrm{p})$ & $8.89 \mathrm{E}-31$ & $-6.1 \%$ & $2.0 \%$ \\
\hline & & ${ }^{48} \mathrm{Ti}(\mathrm{n}, \mathrm{p})$ & $1.26 \mathrm{E}-32$ & $-7.8 \%$ & $2.4 \%$ \\
\hline & & ${ }^{197} \mathrm{Au}(\mathrm{n}, 2 \mathrm{n})$ & $1.37 \mathrm{E}-31$ & $-8.4 \%$ & $3.8 \%$ \\
\hline \multirow{7}{*}{6} & \multirow{7}{*}{26.7} & ${ }^{197} \mathrm{Au}(\mathrm{n}, \gamma)$ & $1.62 \mathrm{E}-26$ & $-0.6 \%$ & $2.2 \%$ \\
\hline & & ${ }^{59} \mathrm{Co}(\mathrm{n}, \gamma)$ & $2.61 \mathrm{E}-27$ & $-9.0 \%$ & $2.0 \%$ \\
\hline & & ${ }^{58} \mathrm{Ni}(\mathrm{n}, \mathrm{p})$ & $5.20 \mathrm{E}-30$ & $-12.1 \%$ & $2.2 \%$ \\
\hline & & ${ }^{54} \mathrm{Fe}(\mathrm{n}, \mathrm{p})$ & $3.64 \mathrm{E}-30$ & $-6.6 \%$ & $2.7 \%$ \\
\hline & & ${ }^{46} \mathrm{Ti}(\mathrm{n}, \mathrm{p})$ & $4.45 \mathrm{E}-31$ & $16.1 \%$ & $6.6 \%$ \\
\hline & & ${ }^{47} \mathrm{Ti}(\mathrm{n}, \mathrm{p})$ & $8.17 \mathrm{E}-31$ & $-3.0 \%$ & $2.0 \%$ \\
\hline & & ${ }^{48} \mathrm{Ti}(\mathrm{n}, \mathrm{p})$ & $1.15 \mathrm{E}-32$ & $-5.9 \%$ & $2.4 \%$ \\
\hline \multirow{6}{*}{7} & \multirow{6}{*}{31.7} & ${ }^{58} \mathrm{Ni}(\mathrm{n}, \mathrm{p})$ & $4.53 \mathrm{E}-30$ & $-0.5 \%$ & $2.3 \%$ \\
\hline & & ${ }^{54} \mathrm{Fe}(\mathrm{n}, \mathrm{p})$ & $3.20 \mathrm{E}-30$ & $4.9 \%$ & $3.3 \%$ \\
\hline & & ${ }^{46} \mathrm{Ti}(\mathrm{n}, \mathrm{p})$ & $4.18 \mathrm{E}-31$ & $22.1 \%$ & $5.3 \%$ \\
\hline & & ${ }^{47} \mathrm{Ti}(\mathrm{n}, \mathrm{p})$ & $8.30 \mathrm{E}-31$ & $-5.7 \%$ & $2.0 \%$ \\
\hline & & ${ }^{48} \mathrm{Ti}(\mathrm{n}, \mathrm{p})$ & $1.15 \mathrm{E}-32$ & $-8.0 \%$ & $3.2 \%$ \\
\hline & & ${ }^{27} \mathrm{Al}(\mathrm{n}, \alpha)$ & $2.07 \mathrm{E}-32$ & $27.3 \%$ & $2.2 \%$ \\
\hline
\end{tabular}

It has been found that the ratio between thermal and fast neutrons in the case of the Teflon insertion is somehow similar to that in the FHR reactor. Therefore, thermal and fast monitors were used in the case of the Teflon insertion. The extended set shown in Tab. V refers to the preliminary results presented in [13] where suitable spectrum indices were proposed for neutron spectrum characterization in the MSR reactor.

\section{CONCLUSIONS}

Calculations of the neutron spectra condensed into three groups which were used to compare ratios of the thermal, intermediate, and fast neutron spectrum in case of filtered neuron field and fields of FHR and MSR 
reactors. FLIBE neutron filter in the LR-0 reactor can be used to reproduce the share of thermal to epithermal neutrons in FHR, whereas teflon has better performance in reproducing thermal to fast share in FHR. For MSR, the share of intermediate to fast neutrons can be simulated to some extent by both filters, but teflon performs better overall.

The more detailed study in the thermal and intermediate neutron spectra was carried out by measuring spectrum indices. $\mathrm{Co}, \mathrm{Au}$ and $\mathrm{Ta}$ foils were used to study the $\mathrm{Cd}$ ratios. Co and $\mathrm{Au}$ are very sensitive since low neutron energies and therefore their Cd ratios are not corresponding neither to the FHR, nor the MSR. It seems that Ta can be used as an acceptable monitor in FLIBE filter to provide information about spectrum similar to FHR. The thermal spectrum of MSR appeared completely different than the filtered spectrum, so other spectral quantities than $\mathrm{Cd}$ ratio must be used for spectrum modelling.

In general, it has been shown that the reaction rates in fluorine-containing filters can be measured with satisfactory uncertainties and the mockup of the fluoride-based reactors can be developed to some extent.

\section{ACKNOWLEDGMENTS}

Presented results were obtained with the use of the infrastructure Reactors LVR-15 and LR-0, which is financially supported by the Ministry of Education, Youth and Sports - project LM2015074 and also financially supported by the Ministry of Education, Youth and Sports Czech Republic - project LQ1603 Research for SUSEN. This work has been realized within the SUSEN Project (established in the framework of the European Regional Development Fund (ERDF) in project CZ.1.05/2.1.00/03.0108 and of the European Structural Funds and Investment Funds (ESIF) in the project CZ.02.1.01/0.0/0.0/15_008/0000293), which is financially supported by the Ministry of Education, Youth and Sports - project LM 2015093 Infrastructure SUSEN.

\section{REFERENCES}

1. E. Losa, et al. "Simulations of Advanced Reactor Cores in Research Light Water Reactor LR-0." Nuclear Engineering and Design, 342, pp. 205-09 (2019).

2. E. Losa, et al. "Neutronic Experiments with Fluorine Rich Compounds at LR-0 Reactor." Annals of Nuclear Energy, 120, pp. 286-95 (2018).

3. M. Koštál, et al. "VVER-1000 Physics Experiments Hexagonal Lattices (1.275 cm Pitch) of Low Enriched U(3.3wt.\% U235)O2 Fuel Assemblies in Light Water With Graphite and Fluoride Salt Insertions in Central Assembly," LR(0)-VVER-RESR-003 CRIT-SPEC, NEA/NSC/DOC(2006)1.

4. M. Koštál et al., "Study of graphite reactivity worth on well-defined cores assembled on LR-0 reactor," Ann. Nucl. En., 87, (2016), 601-611.

5. M. Koštál et al., "Measurement of various monitors reaction rate in a special core at LR-0 reactor," Ann. Nucl. En., 112, (2018), 759-768.

6. M. Koštál et al., "On similarity of various reactor spectra and ${ }^{235} \mathrm{U}$ prompt fission neutron spectrum," Appl. Rad. Isot., 135, (2018), 83-91.

7. M. Koštál et al., "Determining the axial power profile of partly flooded fuel in a compact core assembled in reactor LR-0," Ann. Nucl. En., 90, (2016), 450-458.

8. A. Trkov et al., IRDFF-II: A New Neutron Metrology Library, Nuclear Data Sheets, in preparation

9. C.J. Werner (editor), “MCNP Users Manual - Code Version 6.2," LA-UR-17-29981, (2017).

10. M.B. Chadwick et al. "ENDF/B-VII.0: Next generation evaluated nuclear data library for nuclear science and technology," Nucl. Data Sheets, 107, (2006), 2931.

11. J. Leppänen, et al. (2015) "The Serpent Monte Carlo code: Status, development and applications in 2013." Ann. Nucl. Energy, 82 (2015) 142-150.

12. A. Qualls et al. "Fluoride Salt-Cooled High-Temperature Demonstration Reactor Point Design," research report ORNL/TM-2016/85, Oak Ridge National Laboratory, 2016.

13. E. Losa et al. "Activation Rates Validation to Support MSR Development," Transactions of the American Nuclear Society, 120, 921-922. 